Case Study

\title{
Promotion and support of physical activity in elderly patients on hemodialysis: a case study
}

\author{
Kотомі Sнiота ${ }^{1)^{*}}$, Toshiniko Hashimoto, MD $^{2)}$ \\ 1) Faculty of Sport Science, Waseda University: 2-579-15 Mikajima, Tokorozawa, Saitama 359-1192, \\ Japan \\ 2) Tokyo Women's Medical University Medical Center East, Japan
}

\begin{abstract}
Purpose] The aim of this study was to ascertain the optimum strategy for implementing a physical activity intervention in patients on hemodialysis by investigating the physical characteristics of elderly patients on hemodialysis, and their attitude to physical activity and level of daily activity. [Subjects] The Subject were 10 elderly patients on hemodialysis. [Methods] They wore a physical activity monitor for 1 week. Data obtained were analyzed for hemodialysis and non- hemodialysis days, and two-way analysis of variance was used to compare the number of steps and activity levels. A questionnaire was administered to investigate the stage of psychological preparedness for exercise and attitudes toward/awareness of exercise. [Results] There was no significant difference in the number of steps or exercise levels on hemodialysis and non- hemodialysis days. However, on both types of days, subjects spent long periods not engaged in any activity. Most of their activity was either inactivity or sedentary behavior. [Conclusion] Patients on hemodialysis with low physical activity levels are considered to have poor physical function and exercise tolerance. To maintain and improve the physical function of patients on hemodialysis, it will be necessary to reduce their time spent in inactive, and comprehensive care that covers psychosocial aspects should be provided to promote the proactive improvement of physical activity and their attitudes to exercise. Key words: Hemodialysis, Physical activity, Physical exercise
\end{abstract}

(This article was submitted Nov. 10, 2015, and was accepted Dec. 23, 2015)

\section{INTRODUCTION}

Exercise tolerance generally decreases in patients on hemodialysis (HD) who have diminished musculoskeletal muscle strength and muscle atrophy, reduced muscle blood flow distribution, a decline in cardiopulmonary function, and severely reduced activities of daily living. Previous studies have found that a low level of physical activity (PA) affects physical function, and it has psychological effects that influence the prognosis for survival ${ }^{1-4)}$.

Recently, exercise intervention and high levels of PA have been recommended for patients on HD. Studies have found that these are effective for improving exercise tolerance (i.e., an increased maximum oxygen uptake and anaerobic threshold), pulmonary function (i.e., a lower ventilatory volume at a given submaximal load intensity), cardiac function (i.e., a lower heart rate at a given submaximal load intensity), coronary risk factors (e.g., a lower systolic blood pressure, higher highdensity lipoprotein cholesterol level, and lower neutral fat level), and survival prognosis and for preventing the progression of coronary artery stenotic lesions ${ }^{1,5-11)}$. Although a high level of physical exercise exerts a wide range of beneficial effects, it has so far been difficult to improve the low level of PA in patients on HD. Patients with low levels of PA tend to be elderly women who possess factors that are strongly correlated with diabetes and atherosclerosis ${ }^{9}$.

Particularly, helping such patients maintain a high level of PA is an issue given their level of physical function, and it requires an approach that takes activity patterns, psychological factors, and environmental adjustments into account. In recent years, many elderly patients above 60 years old have started to undergo dialysis treatment above 60 years old, or they have

\footnotetext{
*Corresponding author. Kotomi Shiota (E-mail: shiota@aoni.waseda.jp)

(C)2016 The Society of Physical Therapy Science. Published by IPEC Inc.

This is an open-access article distributed under the terms of the Creative Commons Attribution Non-Commercial No Derivatives (by-nc-nd) License $<$ http://creativecommons.org/licenses/by-nc-nd/4.0/>.
} 
been undergoing dialysis treatment, in addition to those who for a long time (since a young age). As the number of elderly patients on HD increases, it is important to maintain appropriate PA to protect against decreases in physical function and activities of daily living function caused by disuse in daily life. However, in Japan, rehabilitation is not targeted at patients on dialysis during medical treatment. Many patients on dialysis do not readily participate in exercise classes at fitness clubs or communities because of dialysis treatment; consequently, they miss the opportunity to exercise or receive instruction. As there is a lack of a good exercise environment for elderly patients on HD, a large amount of motivation is required to engage such patients in PA. Moreover, elderly patients on HD tend to have low participation in social activity, and they mostly stay indoors, which further reduces their physical levels of PA. In elderly patients on HD, the amount and intensity of PA are important. Many previous studies, however, have focused solely on the amount of PA in terms of the number of steps taken by patients on HD per day, and few have addressed the level of everyday activities that patients on HD are engaged in or their attitudes toward exercise and their state of psychological preparedness. Assessing the activity patterns of patients on HD with a focus on their PA levels and determining their attitudes toward exercise may enable the establishment of support methods that are best suited to raising their levels of activity. The current study aimed to identify the characteristics of elderly patients on HD and their attitudes toward exercise and to ascertain their everyday activity levels by using a PA monitor.

\section{SUBJECTS AND METHODS}

The protocol for the research project conformed to the provisions of the Declaration of Helsinki (as revised in Tokyo in 2004). A researcher described the research purposes, methods, risks, and benefits to the participants. Then consent was obtained for the research study, and a questionnaire to collect personal information was administered to the subjects. There are no conflicts of interest to declare. Subjects were recruited from amongst outpatients who visited two institutions in Japan: a hospital and clinic that specialize in HD treatment. The inclusion criteria were age $\geq 60$ years, $4 \mathrm{~h}$ of HD 3 times/wk renal disease, and HD for $>12$ wk.

To measure PA, subjects wore an accelerometer (Kenz Lifecorder EX 4s version; measurement interval) to evaluate the amount of PA they performed for $1 \mathrm{wk}$, and their number of steps and level of exercise were calculated. They were obligated to wear the device at all times other than in the bath. The imported values for exercise level obtained from the accelerometer included periods in which no activity was recorded, and these periods treated as periods of inactivity. The levels of activity were as follows: PA intensity $<1$, sedentary behavior (SB); 1-3, light-intensity activity (LPA); 4-5, moderate-intensity activity (MPA); and 6-9, vigorous-intensity activity (VPA).

The survey on attitudes toward exercise covered the subjects' psychological state with respect to exercise based on the Transtheoretical Model ${ }^{10}$ ) (a five-stage model comprising precontemplation, no interest at all; contemplation, interested but not yet taking action; preparation, engaging in exercise on an irregular basis; practice, having engaged in continued regular exercise for $<6$ months; and maintenance, having engaged in regular exercise for at least 6 months and acquired the habit of exercising). Items related to their exercise habits (whether they engaged in habitual exercise and the type, frequency, and period for which it was continued) and motivation for exercise (assessed on a four-point scale of agree, somewhat agree, somewhat disagree, and strongly disagree) and items concerning awareness of the need for and the effects of exercise, negative attitudes toward exercise, previous experience of exercise, and wish for instruction about exercise by medical staff (yes/ no answers) were evaluated.

Regarding the analytical methods, accelerometer data were used to calculate the mean time per day spent at each level of PA (inactivity, SB, LPA, MPA, and VPA). The number of steps and time spent at each level of exercise were also calculated separately for each subject on HD and non-HD days. Two-way factorial analysis of variance (ANOVA) was performed with $\mathrm{HD} /$ non-HD days and activity levels as independent variables and activity time as the dependent variable. Bonferroni's method was used for multiple comparisons. The frequencies and percentages of the responses to survey on psychological state were calculated.

\section{RESULTS}

The Subjects were three men (age, $68.7 \pm 2.3$ years; height, $163.7 \pm 1.2 \mathrm{~cm}$; weight, $58.8 \pm 5.0 \mathrm{~kg}$; and dialysis history: $4.6 \pm 2.1$ years) and seven women (age, $65.3 \pm 6.6$ year; height, $152.7 \pm 3.7 \mathrm{~cm}$; weight, $52.4 \pm 11.6 \mathrm{~kg}$; and dialysis history, $2.1 \pm 1.3$ years).

The data of 8 subjects for whom no data were missing were used to calculate the PA levels as the main outcome of this study. In 2 cases with immeasurable levels, the accelerometer did not respond to the level of movement during walking even though the subjects were capable of walking independently.

The number of steps was $2,805.1 \pm 1,742.0$ on HD days and 4,717.0 $\pm 2,991.6$ on non-HD days $(\mathrm{p}=0.069$, effect size $(E S)=-0.64)$, and the difference was not significant (Table 1). The mean number of steps was lower for HD elderly Japanese patients than for non-HD elderly Japanese patients (men, 7,303 steps, and women, 6,705 steps).

To verify whether there was a significant difference between exercise levels on HD and non-HD days, two-way factorial ANOVA was performed with HD/non-HD days and activity levels as independent variables, and activity time as the dependent variable (Tables 1 and 2). This showed a significant interaction $\left(F[4,28]=6.0, p<0.001, n^{2}=0.46\right)$. A test of the simple 
main effect for each level showed that it was not significant for HD/non-HD days $\left(\mathrm{F}[1,70]=0.72, \mathrm{p}=0.79, \mathrm{n}^{2}=0.01\right)$. The simple main effect was significant for the activity level $\left(\mathrm{F}[4,70]=68.9, \mathrm{p}<0.01, \mathrm{n}^{2}=0.79\right)$, and a multiple comparison test showed significant correlations between inactivity and LPA, MPA, and VPA and between SB and LPA, MPA, and VPA. However, there was no significant correlation between inactivity and SB, or between LPA, MPA, and VPA.

The survey on attitudes toward exercise showed that 5 subjects $(50.0 \%)$ were in the precontemplation stage, $3(30.0 \%)$ were in the contemplation stage, and $2(20.0 \%)$ were in the practice stage and in the habit of engaging in regular exercise (Table 2). Motivation to exercise and awareness of the need to exercise was high in 5 subjects (50.0\%) and low in $5(50.0 \%)$. Seven subjects $(70.0 \%)$ disliked exercise and thought of it as too much trouble. Seven subjects $(70.0 \%)$ had previous experience with exercising.

Table 1. Physical activity intensity levels on the dialysis and non-dialysis days

\begin{tabular}{lrrrrrr}
\hline & \multicolumn{3}{c}{ Dialysis day } & \multicolumn{3}{c}{ Non-Dialysis day } \\
\cline { 2 - 6 } & Mean & Median & SD & Mean & Median & SD \\
\hline Steps (steps) & $2,805.1$ & $2,428.3$ & $1,742.0$ & $4,717.0$ & $4,604.7$ & $2,991.6$ \\
Inactivity (min) & 792.5 & 720.4 & 315.8 & 610.4 & 599.4 & 253.7 \\
SB (min) & 557.8 & 639.5 & 282.3 & 619.4 & 811.5 & 268.8 \\
LPA (min) & 20.9 & 20.9 & 10.3 & 32.9 & 34.0 & 19.7 \\
MPA (min) & 7.7 & 2.2 & 10.5 & 11.4 & 5.1 & 14.7 \\
VPA (min) & 0.7 & 0.2 & 1.5 & 1.2 & 0.2 & 1.3 \\
\hline
\end{tabular}

SB: sedentary behavior; LPA: light-intensity physical activity; MPA: moderate-intensity physical activity; VPA: vigorousintensity physical activity

Table 2. Results concerning psychological state

\begin{tabular}{|c|c|c|c|}
\hline & & $\mathrm{n}=10$ & $\%$ \\
\hline \multirow[t]{3}{*}{ TTM stage } & Precontemplation & 5 & 50.0 \\
\hline & Contemplation & 3 & 30.0 \\
\hline & Practice & 2 & 20.0 \\
\hline \multirow[t]{2}{*}{ Ex habit } & Yes & 2 & 20.0 \\
\hline & No & 8 & 80.0 \\
\hline \multirow[t]{2}{*}{ Habitual ex type } & Group ex & 1 & \\
\hline & Walking & 1 & \\
\hline \multirow[t]{3}{*}{ Habitual ex frequency/w } & Over 3 days & 1 & 10.0 \\
\hline & 2 days & 1 & 10.0 \\
\hline & None & 8 & 80.0 \\
\hline \multirow[t]{3}{*}{ Habitual ex duration } & Over 1 year & 1 & 10.0 \\
\hline & $1-6$ months & 1 & 10.0 \\
\hline & Less than 1 month & 8 & 80.0 \\
\hline \multirow[t]{2}{*}{ Motivation for ex } & Agree & 5 & 50.0 \\
\hline & Somewhat disagree & 5 & 50.0 \\
\hline \multirow[t]{2}{*}{ Awareness of the need for ex } & Agree & 5 & 50.0 \\
\hline & Somewhat agree & 5 & 50.0 \\
\hline \multirow[t]{4}{*}{ Negative attitude toward ex } & Agree & 1 & 10.0 \\
\hline & Somewhat agree & 6 & 60.0 \\
\hline & Somewhat disagree & 2 & 20.0 \\
\hline & Disagree & 1 & 10.0 \\
\hline \multirow[t]{2}{*}{ Effect of ex } & Agree & 5 & 50.0 \\
\hline & Somewhat & 5 & 50.0 \\
\hline \multirow[t]{2}{*}{ Previous experience of ex } & Yes & 7 & 70.0 \\
\hline & No & 3 & 30.0 \\
\hline
\end{tabular}

TTM: Transtheoretical Model; ex: exercise 


\section{DISCUSSION}

The purpose of this study was to ascertain the characteristics of the PA levels and attitudes toward PA of elderly patients on HD. We found that their mean number of steps per day was lower than the reference value for non-HD elderly individuals. Additionally, although there was no significant difference in the numbers of steps or activity levels on HD and non-HD days, the time spent in inactivity was long on both days, and most activity was SB. Over $80.0 \%$ of the subjects were not in the habit of exercising, and although $70.0 \%$ had previous experience with exercising, their awareness of the need to exercise was now low (50.0\%); additionally, they tended to harbor negative feelings about exercising $(70.0 \%)$.

The decline in physical function seen in patients on HD was due to the effect of chronic renal failure and the fact that they were leading sedentary lifestyles, with low levels and intensities of exercise, which is also an important factor. In a previous study of PA, 795 (35.1\%) of among 2,264 patients on HD in the United States, were not engaged in any type of PA or exercise $^{2)}$. A follow-up investigation of those patients 1 year later found that heart disease and peripheral complications were more frequent among those who had not engaged in exercise or PA, and the risk of death after 1 year was 1.62 times higher than that of those who did engage in exercise or PA. A 10 year follow-up study of patients who engaged in regular aquatic exercise and those who were inactive also found that mortality was higher for patients on HD ${ }^{13)}$.

In terms of patterns of PA, there were no great differences in the average values on HD and non-HD days, but the absence of a difference in the number of steps may have been due to the wide standard deviation. In a previous study of PA on HD and non-HD days, Majchrzak et al. ${ }^{12,14,15)}$ showed that patients on HD had particularly low activity levels on HD days. They found that factors contributing to the decrease in PA on HD days included HD-induced fatigue and postural hypotension ${ }^{14,16)}$ Patients on HD also spend about $>10 \mathrm{~h} /$ wk in treatment-associated rest, hemostasis after HD, and post-HD fatigue with a low blood pressure. Focusing on the activity intensity patterns in this study, subjects spent the longest amount of time inactive, and even when they were active, the time spent in SB, which involved sitting or a similar activity, was extremely long on both HD and non-HD days. This indicated that patients on HD generally lead an inactive, sedentary lifestyle. Johansen et al. ${ }^{17)}$ used accelerometry to measure activity levels in patients on HD over a 1-wk period and showed that patients on HD had significantly lower levels of activity than those of healthy individuals who were leading a sedentary lifestyle. Guidelines in many countries, Japan included, recommend that elderly people take at least 6,000 steps a day and engage in around 15 min of moderate PA, but patients on HD do not achieve this even on non-HD days.

The length of these periods of inactivity and bed rest minimizes the effect of gravity, meaning that gravity-resisting muscles are not subjected to gravity for continued periods, resulting in inactivity. Thus, they develop disuse muscle atrophy, which reduces muscle strength, generating a vicious cycle whereby declining physical function factors and PA exert a negative effect on each other $\left.{ }^{15}, 16,18,19\right)$. Patients on HD are therefore recommended to be proactive in raising their levels of PA and incorporating exercise therapy. However, the question of the extent to which the PA of patients on HD can be increased is an important one. As shown by subjects in this study, patients on HD may have a low awareness of exercise, and even if they do regard it as necessary, they may not engage in it due to negative attitudes.

A wide range of intervention methods are now being used to encourage PA by patients on HD, including intervention on non-HD days and before and during HD, as well as the use of home exercises. Many patients on HD also have complications and may be worried about heart failure or hypertension immediately before HD and postural hypertension immediately after HD. Thus, it is necessary to encourage PA that is best suited to each individual. Counseling and efforts on the part of staff involved in HD to encourage patients on HD to increase their levels of regular physical exercise are also required ${ }^{5)}$. The present findings also suggested that patients on HD are looking for support from medical staff. According to Bennett et al. ${ }^{6,20)}$, specialist staff and encouragement and commitment on the part of medical staff are factors that contribute to a successful continuous program. For medical staff, possessing the appropriate knowledge is also a factor that helps increase the level of physical exercise in patients on HD. Improving the level of physical exercise has been shown to have a beneficial effect on mental health and physical function ${ }^{16,21)}$, and intervention through appropriate PA may provide the impetus for patients on HD to generate a virtuous circle.

This study only included a small number of subjects, and thus we did not attempt to elucidate a causal relationship between PA and body strength characteristics. Patients on HD with low levels of PA, however, reportedly also have poor physical function, exercise tolerance, and survival prognosis ${ }^{22}$. In addition, this study focused on intensity rather than the number of steps. As may be understood from the results of this study, it is significantly difficult for patients to exercise on their own in the absence of exercise instructors due to their low motivation for exercise. In recent years, from the perspective of health-related behavioral science ${ }^{23)}$, however, emphasis has been placed on eliminating negative factors, such as reducing sitting time daily and changing patterns of inactive time (i.e., sitting behavior), rather than on positive factors for improving PA by promoting exercises, as was the case in this study. Thus, changing the daily PA pattern is important for patients on HD. Therefore, appropriate PA guidance is required, especially at medical institutions without stationed specialists to help with exercise. In the 2 cases with immeasurable PA levels in this study, the accelerometer did not respond to the levels of movement during walking even though the patients could walk independently. Determining indexes of the amount of physical exertion for patients on dialysis is important. Furthermore, a comprehensive care program that includes guidance on improving PA and the psychosocial aspects of exercise is needed. 


\section{ACKNOWLEDGEMENTS}

We are sincerely grateful for the cooperation from Hiroshi Horibe (ME), Makiko Kobayashi (ME), Yasuhiro Iguchi (MD), and other staff of the Shinsui Dialysis Clinic, as well as the patients. We would also like to thank Editage for editing our manuscript.

\section{REFERENCES}

1) Longenecker JC, Coresh J, Powe NR, et al.: Traditional cardiovascular disease risk factors in dialysis patients compared with the general population: the CHOICE Study. J Am Soc Nephrol, 2002, 13: 1918-1927. [Medline] [CrossRef]

2) O'Hare AM, Tawney K, Bacchetti P, et al.: Decreased survival among sedentary patients undergoing dialysis: results from the dialysis morbidity and mortality study wave 2. Am J Kidney Dis, 2003, 41: 447-454. [Medline] [CrossRef]

3) Bae YH, Lee SM, Jo JI: Aerobic training during hemodialysis improves body composition, muscle function, physical performance, and quality of life in chronic kidney disease patients. J Phys Ther Sci, 2015, 27: 1445-1449. [Medline] [CrossRef]

4) Cho H, Sohng KY: The effect of a virtual reality exercise program on physical fitness, body composition, and fatigue in hemodialysis patients. J Phys Ther Sci, 2014, 26: 1661-1665. [Medline] [CrossRef]

5) Aucella F, Valente GL, Catizone L: The role of physical activity in the CKD setting. Kidney Blood Press Res, 2014, 39: 97-106. [Medline] [CrossRef]

6) Bennett PN, Breugelmans L, Barnard R, et al.: Sustaining a hemodialysis exercise program: a review. Semin Dial, 2010, 23: 62-73. [Medline] [CrossRef]

7) Goldberg AP, Geltman EM, Gavin JR 3rd, et al.: Exercise training reduces coronary risk and effectively rehabilitates hemodialysis patients. Nephron, 1986, 42: 311-316. [Medline] [CrossRef]

8) Heiwe S, Jacobson SH: Exercise training in adults with CKD: a systematic review and meta-analysis. Am J Kidney Dis, 2014, 64: 383-393. [Medline] [CrossRef]

9) Johansen KL, Painter P: Exercise in individuals with CKD. Am J Kidney Dis, 2012, 59: 126-134. [Medline] [CrossRef]

10) Kouidi E: Exercise training in dialysis patients: why, when, and how? Artif Organs, 2002, 26: 1009-1013. [Medline] [CrossRef]

11) Painter P, Moore G, Carlson L, et al.: Effects of exercise training plus normalization of hematocrit on exercise capacity and health-related quality of life. Am J Kidney Dis, 2002, 39: 257-265. [Medline] [CrossRef]

12) Marcus BH, Selby VC, Niaura RS, et al.: Self-efficacy and the stages of exercise behavior change. Res Q Exerc Sport, 1992, 63: 60-66. [Medline] [CrossRef]

13) Pechter Ü, Raag M, Ots-Rosenberg M: Regular aquatic exercise for chronic kidney disease patients: a 10-year followup study. Int J Rehabil Res, 2014, 37: 251-255. [Medline] [CrossRef]

14) Majchrzak KM, Pupim LB, Chen K, et al.: Physical activity patterns in chronic hemodialysis patients: comparison of dialysis and nondialysis days. J Ren Nutr, 2005, 15: 217-224. [Medline] [CrossRef]

15) Ponngeon O, Chaunchaiyakul R, Vareesangthip K, et al.: Home-based walking program increases leg muscle strength in hemodialysis patients. J Phys Ther Sci, 2011, 23: 345-348. [CrossRef]

16) Stack AG, Murthy B: Exercise and limitations in physical activity levels among new dialysis patients in the United States: an epidemiologic study. Ann Epidemiol, 2008, 18: 880-888. [Medline] [CrossRef]

17) Johansen KL, Chertow GM, Ng AV, et al.: Physical activity levels in patients on hemodialysis and healthy sedentary controls. Kidney Int, 2000, 57: 2564-2570. [Medline] [CrossRef]

18) Johansen KL, Painter P, Kent-Braun JA, et al.: Validation of questionnaires to estimate physical activity and functioning in end-stage renal disease. Kidney Int, 2001, 59: 1121-1127. [Medline] [CrossRef]

19) Kouidi E, Albani M, Natsis K, et al.: The effects of exercise training on muscle atrophy in haemodialysis patients. Nephrol Dial Transplant, 1998, 13: 685-699. [Medline] [CrossRef]

20) Silva LC, Marinho PE: Knowledge among nephrologists about the importance of exercise in the intradialytic period. J Phys Ther Sci, 2015, 27: 2991-2994. [Medline] [CrossRef]

21) Nowicki M, Murlikiewicz K, Jagodzińska M: Pedometers as a means to increase spontaneous physical activity in chronic hemodialysis patients. J Nephrol, 2010, 23: 297-305. [Medline] 
22) Morishita Y, Nagata D: Strategies to improve physical activity by exercise training in patients with chronic kidney disease. Int J Nephrol Renovasc Dis, 2015, 9: 19-24. [Medline] [CrossRef]

23) Cole JA, Tully MA, Cupples ME: They should stay at their desk until the work's done: a qualitative study examining perceptions of sedentary behaviour in a desk-based occupational setting. BMC Res Notes, 2015, 8: 1-9. 